\title{
Recovery of Ionic Liquids from Wastewater by Nanofiltration
}

\author{
José F. Fernández*, Robert Bartel, Ulrike Bottin-Weber, Stefan Stolte and Jorg Thöming
}

UFT-Centre for Environmental Research and Sustainable Technology, University of Bremen, Leobener Str., 28359 Bremen, Germany

\begin{abstract}
In this study, the possibility to recover ionic liquids from their respective wastewater by nanofiltration was tested in two case studies. The experiments were performed using a commercial dead-end stirred cell and/or a cross-flow cell especially developed for this purpose. Hydrophilic ionic liquids are being presently used for the dissolution of cellulose and its further regeneration by water addition. Wastewater containing a mixture of 1-butyl-3-methylimidazolium chloride (IM14 Cl) and 1-butyl-3-methylimidazolium acetate (IM14 1COO) was treated by nanofiltration and the ionic liquids were recovered as an aqueous solution which is also almost free of undesired by-products. On the contrary, hydrophobic ionic liquids are commonly used in biphasic systems to perform either enzymatic or whole-cell biotransformations. Wastewater containing hydrophobic ionic liquids derived from the conversion of 2-octanone to 2-octanol was also tested, and the ionic liquids used can be recovered as a separate phase by concentrating them beyond the solubility limit. The effect of other wastewater components on the recovery was also investigated with the ionic liquid 1-hexyl-3-methylimidazolium bis (trifluoromethylsulfonyl) amide, IM16 (CF3SO2)2N. Furthermore, using model solutions of 1-hexyl-1-methylpyrrolidinium bis (trifluoromethylsulfonyl) amide, Pyr16 (CF3SO2)2N, it could be evidenced that the formation of a new phase of ionic liquid during the concentration process follows a nucleation-growth mechanism. In this case, up to $69 \%$ of the ionic liquid originally present in the feed was separated. Additionally, the effective recovery rate was duplicated up to $33 \%$ by using a coalescence filter. Some suggestions to increase both theoretical and effective recovery rates are also discussed.
\end{abstract}

\section{Introduction}

Ionic liquids are compounds that consist exclusively of ions, and have melting points below $100^{\circ} \mathrm{C}[1]$. Only few industrial applications that use ionic liquids are known to public [2], but studies about their potential uses grow exponentially every year. Up to date, no references have been found for industrial applications using ionic liquids in which recovery and/or removal processes are taking place. All those industrial applications with commercial relevance reuse the ionic liquid regularly and seem to be waste-free [3].

This situation could indicate that there are still some unsolved problems related with handling wastes containing ionic liquids. If the process generates such wastes, the operation costs for make-up of ionic liquid should be considered, as well as the environmental acceptability of the waste in terms of (eco)toxicity and biodegradability. However, these and other issues of importance for the lifecycle of ionic liquids have been commonly neglected [4], and the majority of ionic liquids actually used are considered to be low or not environmental compatible [5].

Processes such as the dissolution and regeneration of cellulose or the biocatalytic production of chiral alcohols can be classified as potential applications of ionic liquids which are close to production scale, but before it happens they must achieve a high lifetime of the ionic liquids used. Thus methods are needed either to keep track of by-product formation and impurity accumulation, or to recover ionic liquid from wastewater [6-8].

Ionic liquids can be used as non-derivatizing solvents for cellulose [9]. Under shear strain, temperature and vacuum, the celluloseionic liquid suspension is transformed into a homogeneous, nearly water free solution, which is shaped into fibers or foils. Stabilizers like sodium hydroxide and propyl gallate are added to prevent cellulose degradation. The regeneration is achieved by precipitation in an aqueous spinning bath, which dissolves completely the ionic liquid [10]. By using hydrophilic ionic liquids containing 1-butyl-3methylimidazolium (IM14) or 1-ethyl-3-methylimidazolium (IM12) cations, either with chloride $(\mathrm{Cl})$ or acetate $(1 \mathrm{COO})$ anions, is possible to prepare solutions with cellulose concentrations exhibiting highly technical importance [11]. The fibers obtained are very similar to those obtained by the Lyocell process, but presently the recovery of the ionic liquid is more energy-consuming due to the required complete removal of water by evaporation [12]. Additionally, it is expected that side reactions (chromophores formation, cellulose degradation and increased consumption of stabilizers) also take place $[13,14]$.

Industrial processes for the production of optical active secondary alcohols employing alcohol dehydrogenase (ADH) enzymes are widely used [15]. Several studies have demonstrated that a biphasic ionic liquid-water system can improve the asymmetric reduction of ketones in comparison to conventional aqueous systems [16]. Hydrophobic ionic liquids containing the bis(trifluoromethylsulfonyl) amide anion, (CF3SO2)2N, have been successfully tested, either using isolated enzymes [17,18] or whole cells [19-21]. In both cases, the cofactor regeneration should be carried out parallel to the conversion of substrate to product and it could be achieved using an auxiliary cosubstrate (2-propanol, sodium formate or glucose) that is oxidized by a second enzyme or even by the same enzyme used for the reaction $[17,22]$. The recycling of the ionic liquid phase over 25 process cycles, without losing productivity and/or degradation of the ionic liquid, was recently reported [23]. However, even though the hydrophobic ionic liquids exhibit low water solubility, their losses in the exhausted aqueous phase can be considerable, and the associated economical and environmental impacts should be taken into account [24].

*Corresponding author: José F. Fernández, UFT - Centre for Environmental Research and Sustainable Technology, University of Bremen Tel: +49 421 21863373 - Fax: +49 421 2188297; E-mail: jo_fe@uni-bremen.de

Received June 20, 2011; Accepted July 15, 2011

Citation: Fernández JF, Bartel R, Bottin-Weber U, Stolte S, Thöming J (2011) Recovery of Ionic Liquids from Wastewater by Nanofiltration. J Membra Sci Technol S4:001. doi:10.4172/2155-9589.S4-001

Copyright: (c) 2011 Fernández JF, et al. This is an open-access article distributed under the terms of the Creative Commons Attribution License, which permits unrestricted use, distribution, and reproduction in any medium, provided the original author and source are credited. 
The simplest method to remove water from an ionic liquid would be evaporation, but the high energy costs associated with evaporating water from a solution of ionic liquid makes this method impractical [25]. At the present, only few studies have been focused on the separation of aqueous solutions containing ionic liquids. Some of them considered salting-out processes using electrolytes [26-30], carbohydrates [31-33] and carbon dioxide [34,35]. However, nanofiltration appears also to be a suitable method due to the ionic nature of these compounds [36].

Nanofiltration membranes can be chosen to retain the ionic liquid, if the aim is to concentrate it; or to allow the selective separation of the ionic liquid from other components present in solution, if the aim is to obtain an ionic liquid free from undesired compounds. Studies related to the separation of hydrophilic ionic liquids from aqueous solution have been already published; either by using single ionic liquids $[36,37]$ or mixtures containing an ionic liquid and a second compound $[36,38,39]$. However, to the best of our knowledge, there are no earlier references about the use of nanofiltration for the concentration of aqueous solutions of hydrophobic ionic liquids.

In this study, the first experiments to recover ionic liquids from real wastewater by nanofiltration have been carried out using samples from the applications described above. Additionally, the recovery of hydrophobic ionic liquids was studied in detail by using synthetic aqueous solutions.

\section{Experimental}

\section{Materials}

All wastewaters were used as received, after having stabilized the temperature at $298 \mathrm{~K}$ for one day. The wastewater from the dissolution of cellulose comprised an aqueous mixture (about 85:15) of 1-butyl3-methylimidazolium chloride (IM14 Cl, MW = $174.67 \mathrm{~g} / \mathrm{mol}$ ) and 1-butyl-3-methylimidazolium acetate (IM14 1COO, MW = $198.26 \mathrm{~g} /$ mol), with a content of ionic liquid around $18-20 \%$, and exhibiting a dark gold colour. It was provided by the Thuringian Institute of Textile and Plastic Research (TITK, Germany).

Two reaction mixtures from the reduction of 2-octanone catalyzed by the Lactobacillus brevis alcohol dehydrogenase (LB-ADH), containing 1-hexyl-3-methylimidazolium bis(trifluoromethylsulfonyl) amide (IM16 (CF3SO2)2N, MW = $447.42 \mathrm{~g} / \mathrm{mol}$ ) and 1-butyl-1methylpyrrolidinium bis(trifluoromethylsulfonyl)amide (Pyr14 $(\mathrm{CF} 3 \mathrm{SO} 2) 2 \mathrm{~N}, \mathrm{MW}=422.41 \mathrm{~g} / \mathrm{mol})$, were provided by Julich Chiral Solutions (now Codexis, USA). These mixtures contained initially $30 \% \mathrm{v} / \mathrm{v}$ of ionic liquid, $1 \mathrm{M}$ 2-octanone, $20 \mathrm{U} / \mathrm{mL} \mathrm{LB}-\mathrm{ADH}$ and $1 \mathrm{mM}$ $\mathrm{NADP}$ in $0.2 \mathrm{M}$ phosphate buffer $(\mathrm{pH}=7.0)$. Conversion of 2-octanone to 2 -octanol was reported around $60 \%$ for the ionic liquid based on the Pyr14 cation, while more than $90 \%$ conversion was reported for that based on the IM16 cation. The differences are related with the cofactor regeneration method used: in the first case 2-propanol was oxidized to acetone, while in the second case glucose was oxidized by means of glucose dehydrogenase (GDH). After reaction, the ionic liquid phase was completely separated by sedimentation after 5 hours.

The aqueous phase from whole-cell biotransformation of 2 -octanone into 2-octanol, contained initially $20 \% \mathrm{v} / \mathrm{v}$ of 1 -hexyl1-methylpyrrolidinium bis(trifluoromethylsulfonyl)amide (Pyr16 $(\mathrm{CF} 3 \mathrm{SO} 2) 2 \mathrm{~N}, \mathrm{MW}=450.46 \mathrm{~g} / \mathrm{mol}), 0.3 \mathrm{M}$ 2-octanone, $50 \mathrm{~g} / \mathrm{L}$ dry biomass and $1 \mathrm{M}$ sodium formate in $0.5 \mathrm{M}$ phosphate buffer $(\mathrm{pH}=$ 6.5). The biomass contained an Escherichia coli strain able to produce the Lactobacillus brevis alcohol dehydrogenase (LB-ADH) and the Candida boidinii formate dehydrogenase (CB-FDH) for the cofactor regeneration. After reaction (conversion around 80-90\%), the ionic liquid was separated by centrifugation from cells and aqueous phase. This sample was provided by the Institute of Biochemical Engineering, Technical University Munich (TUM, Germany)

For synthetic solutions, two ionic liquids (Merck KGaA) were used as received: IM16 (CF3SO2)2N and Pyr16 (CF3SO2)2N. To reduce the influence of additional ions, deionised water with an electric conductivity lower than $2 \mu \mathrm{S} / \mathrm{cm}$ was used to prepare such solutions. Finally, three commercially available nanofiltration membranes were employed: FilmTec NF-90 and FimTec NF-270 (Dow Chemical, USA), and Desal DK (GE Osmonics, USA).

\section{Dead-end nanofiltration experiments}

For the experiments, a stirred dead-end cell HP4750 (Sterlitech Corporation, USA) with a membrane active area of $13.9 \mathrm{~cm}^{2}$ was used. The cell consists in three major components: the cell body with removable top and bottom parts, the stir bar assembly and standard couplings. In addition, a magnetic stirrer $(230 \mathrm{VAC}, 50 \mathrm{~Hz})$ was used and nitrogen with purity 5.0 (Linde AG, Germany) was selected as source of gas pressure.

Membranes were placed in deionised water for two days before use to assure complete swelling. Each swollen membrane was conditioned with deionised water by increasing pressure progressively until a pressure of 40 bar was reached. After that, the desired amount of feed $\left(100-150 \mathrm{~mL}\right.$ at $\left.25^{\circ} \mathrm{C}\right)$ was filled in the cell, the pressure difference was fixed at 35 bar and permeate was removed continuously until the desired ratio permeate volume to feed volume (process recovery) was reached. The time required to obtain different volumes was measured, in order to calculate permeate fluxes. Samples of feed, retentate and cumulated permeate were taken for later analysis and used to calculate retention $(\mathrm{R})$ and ionic liquid recovery $(\mathrm{Rec})$, as follows:

$$
R=1-\frac{C_{p}}{C_{F}}
$$

where

R: Retention, rejection (-)

$\mathrm{C}_{\mathrm{F}}$ : Concentration of ionic liquid in feed $(\mathrm{g} / \mathrm{L})$

$\mathrm{C}_{\mathrm{p}}$ : Concentration of ionic liquid in permeate $(\mathrm{g} / \mathrm{L})$

$$
\operatorname{Rec}=\frac{Q_{F} \cdot C_{F}-Q_{P} \cdot C_{P}-Q_{R} \cdot C_{R}}{Q_{F} \cdot C_{F}}
$$

where:

Rec: Recovery of ionic liquid (total) (-)

$\mathrm{Q}_{\mathrm{F}}$ : Volume of feed (L)

$\mathrm{Q}_{\mathrm{p}}$ : Volume of permeate (L)

$\mathrm{Q}_{\mathrm{R}}$ : Volume of retentate $(\mathrm{L})$

$\mathrm{C}_{\mathrm{R}}$ : Concentration of ionic liquid in retentate $(\mathrm{g} / \mathrm{L})$

\section{Cross-flow nanofiltration experiments}

Experiments were carried out using a laboratory scale-test cell developed and constructed at the University of Bremen (Figure 1). The membrane active area is equal to $270 \mathrm{~cm}^{2}$, distributed in two identical modules connected in series. The use of a spacer in the feed channel and a high cross flow velocity of $0.5 \mathrm{~m} / \mathrm{s}$ ( $45 \mathrm{~L} / \mathrm{h}$ ) should create enough turbulence to reduce concentration polarization effects.

The equipment was designed for the batch filtration of 5 liter feed. 


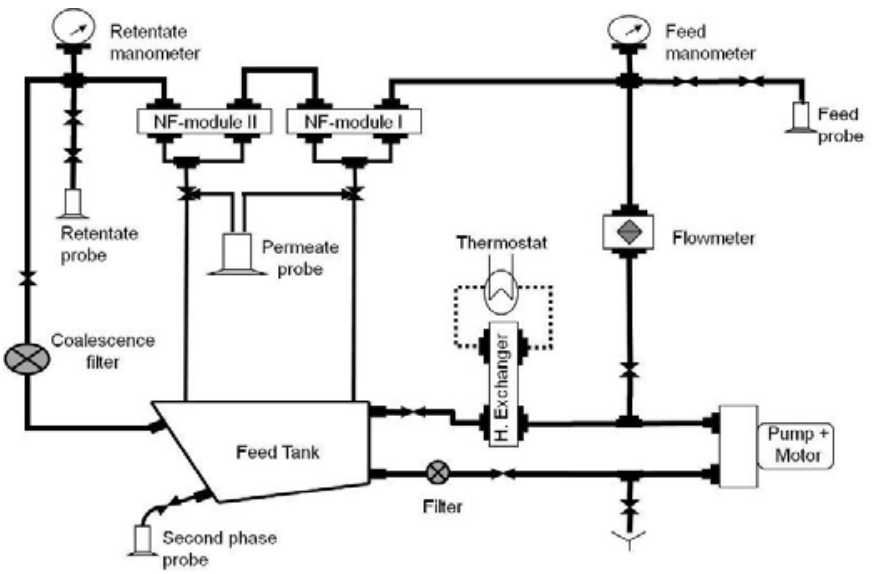

Figure 1: Schematic diagram of the equipment using a cross-flow cell used in this study.

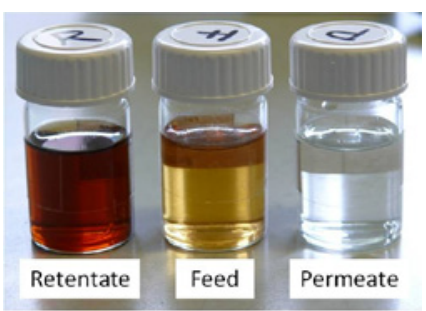

Figure 2: Visual differences between the retentate and permeate samples compared to the feed sample before a single step nanofiltration process using the NF-270 membrane. The wastewater contained a mixture of IM14 Cl and IM14 1COO. The compounds responsible for color were mostly retained by the membrane.

The tank was made of Plexiglas to observe feed appearance changes. The equipment has a plunger pump (Speck Triplex, Germany) with a maximal pressure of $140 \mathrm{bar}$, maximal output of $4 \mathrm{~L} / \mathrm{min}$ and stainless steel valve casings and wetted parts. The temperature of the solution in the system was maintained at $25 \pm 0.01^{\circ} \mathrm{C}$, by using a plate heat exchanger (FeRo, Germany) coupled with a thermostat (Lauda, Germany). The feed pressure and the feed flow rate were adjusted by needle valves. An oval gear-wheel flowmeter (Profimess, Germany) with an operating range of $14-80 \mathrm{~L} / \mathrm{h}$ was used. The pipelines $(1 / 4$ " for feed and retentate, and $1 / 8$ " for permeate), the coalescence filter housing, the particle filter, the manometers (0-60 bar), and all valves and fittings used are Swagelok parts (Best Fluidsysteme, Germany). For the coalescence filter housing a filter element (MTS Filtertechnik, Germany) of stainless steel was also used.

Swollen membrane pieces were placed in the modules and conditioned progressively with deionised water. This conditioning process comprises five different pressure levels (between 0 and 35 bar), and pressure was kept 30 minutes for each pressure level, except for the last one (45 minutes). After that the deionised water was completely discharged and the solution of ionic liquid was filled in the tank. The system was operated at 35 bar during 30 minutes in the full recirculation mode, while both retentate and permeate were continuously returned to the feed tank. After that, the concentration process started under the following operation parameters: $25^{\circ} \mathrm{C}, 35$ bar and $0.5 \mathrm{~m} / \mathrm{s}$. A feed sample for analysis was taken direct from the feed tank before starting to collect permeate, which was collected step-by-step in bottles $(250 \mathrm{~mL})$ until a process recovery around $50 \%$ was reached. For each permeate sample, the collecting time was measured and the exact volume was later determined with a graduated cylinder. For each bottle of permeate a sample was taken for analysis. The retentate was collected in a separate bottle and a sample for analysis was also taken after two days settling. After rinsing the filtration equipment with deionised water, ionic liquid were also determined in the rinsing water. That means that the effective recovery of ionic liquid must be calculated, as follows:

$$
\text { Rec-eff - lab }=\frac{Q_{F} \cdot C_{F}-Q_{P} \cdot C_{P}-Q_{R} \cdot C_{R}-Q_{R W} \cdot C_{R W}}{Q_{F} \cdot C_{F}}
$$

Rec-eff-lab: Effective recovery of ionic liquid at lab scale (-)

$$
\begin{aligned}
& \mathrm{Q}_{\mathrm{RW}} \text { : Volume of rinsing water }(\mathrm{L}) \\
& \mathrm{C}_{\mathrm{RW}} \text { : Concentration of ionic liquid in rinsing water }(\mathrm{g} / \mathrm{L})
\end{aligned}
$$

\section{Analytical methods}

The ion-chromatography (IC) measurements to determine concentrations of ionic liquid were carried out using a Metrohm 881 Compact IC system (Metrohm, Switzerland). It is equipped with an online eluent degasser, a $20 \mu \mathrm{L}$ injection loop and a conductimetric detector maintained at $30^{\circ} \mathrm{C}$. All chromatographic data were recorded by the MagICNet 1.1 compact software. All measurements were done as duplicate and several dilutions factors were used.

For cation separations a C4 ion exchange column (50 x $4.0 \mathrm{~mm}$ ID and $5 \mu \mathrm{m}$ mean particle size) coupled with C4 Guard and RP Guard was used. A flow rate of $0.9 \mathrm{~mL} / \mathrm{min}$ of eluent $\left(2 \mathrm{mM} \mathrm{HNO}_{3}, 30 \% \mathrm{CH}_{3} \mathrm{CN}\right)$ was applied. For the determination of anions an A Supp ion exchange column ( $50 \times 4.0 \mathrm{~mm}$ ID and $5 \mu \mathrm{m}$ mean particle size) coupled with A Supp 4/5 Guard and RP Guard was used. A flow rate of $0.7 \mathrm{~mL} / \mathrm{min}$ of eluent $\left(3.2 \mathrm{mM} \mathrm{Na}_{2} \mathrm{CO}_{3}, 2 \mathrm{mM} \mathrm{NaHCO}, 35 \% \mathrm{CH}_{3} \mathrm{CN}\right.$ or $1 \mathrm{mM}$ $\mathrm{NaHCO}_{3}, 3.9 \mathrm{mM} \mathrm{H}_{3} \mathrm{PO}_{4}, 30 \% \mathrm{CH}_{3} \mathrm{CN}$ ) was applied.

By using synthetic solutions of ionic liquids, independent ICmeasurements of cation and anion for different samples were also carried. No matter which specie was determined, both concentrations were almost the same, verifying that no ion exchange occurs during the filtration process (the risk was minimized using deionised water), but also simplifying the analytic work.

Electrical conductivity was measured with an inoLab Cond-Level2-Meter using an epoxy TetraCon 325 probe (WTW GmbH, Germany). The temperature was kept constant at $25^{\circ} \mathrm{C}$ with a thermostat (Lauda, Germany). All measurements were done as duplicate. An estimation of the content of cellulose degradation by-products was obtained using the anthrone method, applied for the colorimetric determination of carbohydrates [40]. The concentration of ionic liquids in wastewaters from cellulose dissolution was determined directly by the supplier using its own calibration curves for refractive index versus ionic liquid content, method already established for such a task [41].

\section{Results and Discussion}

\section{Recovery of hydrophilic ionic liquids from wastewater}

Ionic liquids used for the dissolution and regeneration of cellulose are highly water soluble (> $1000 \mathrm{~g} / \mathrm{L}$ ), which constitutes a challenge during their recovery from aqueous solutions. Furthermore, after the regeneration of cellulose by adding water to the mixture cellulose-ionic liquid a colored wastewater is obtained, indicating that compounds such as stabilizers and by-products are present. They could be able to disturb a further cellulose dissolution step if they are not previously 
separated from the ionic liquid. Thus, the first target of the recovery scheme by nanofiltration is to purify the wastewater by reducing the content of such disturbing compounds. The membrane FilmTec NF-270 was selected for this task in order to test the feasibility of the separation.

After a single filtration step in the dead-end cell, $70 \%$ of the feed was recovered as permeate $\left(\mathrm{V}_{\mathrm{P}} / \mathrm{V}_{\mathrm{F}}=70 \%\right)$. It was possible to appreciate the magnitude of the separation by visual differences between the colors of the resulting streams: the retentate exhibited a caramel color, while permeate was colorless (Figure 2). That means that chromophores formed as condensation products of carbohydrates upon thermal, acidic or basic treatment [42] and those formed from propyl gallate as a radical trap [43] can be retained successfully by the membrane, despite they are present in ppm and ppb concentration ranges [44].

Moreover, it is known that solutions of cellulose in 1-alkyl-3methylimidazolium ionic liquids, both the ionic liquid and the cellulose are not inert [45]. Then a high complexity of the wastewater matrix from the regeneration bath is expected and the problems related to the separation of ionic liquid and sugar products from water have first to be faced and solved [46]. Consequently, it was not possible to isolate the ionic liquid and thus quantify its concentration due the clogging of the ion chromatography columns even for very high dilution factors. Then, indirect measurements were conducted in order to quantify the extent of the separation. Conductivity measurements were $49 \mathrm{mS} / \mathrm{cm}$ for retentate, $47 \mathrm{mS} / \mathrm{cm}$ for feed and $45 \mathrm{mS} / \mathrm{cm}$ for permeate. With help of refraction index measurements, it could be determined that the concentration of the ionic liquid in permeate is around $15 \%$, compared to the original $19 \%$ in feed. On the other hand, the content of cellulose degradation by-products determined by the anthrone method was $52 \mathrm{mg} / \mathrm{L}$ in retentate, $28 \mathrm{mg} / \mathrm{L}$ in feed and $18 \mathrm{mg} / \mathrm{L}$ in permeate, respectively. These results indicate that the the membrane employed is more selective for the by-products of cellulose degradation $(36 \%$ retention), but the separation of the ionic liquid is not favored $(21 \%$ retention), which can be associated with the low molecular weight of the ionic liquids used

After a single filtration step, the ionic liquid from permeate has still a content of cellulose degradation by-products too high to be directly reused in the cellulose dissolution process. Then, a further treatment of the permeate sample was conducted by filtering it two more times using the NF-270 membrane in the dead-end cell. The normalized permeate flux increases as a function of the feed recovery rate (that is, the ratio of permeate volume to feed volume) with increasing number of filtration steps (Figure 3). During the first step, the concentration of by-products in the retentate stream leads to a pronounced decrease in the permeate flux, but after their progressively separation as part of the retentate sample, the reduction of the permeate flux is less pronounced during the second step and remains almost constant after three filtration steps.

By measuring the refractive index of the permeate sample from the third step a concentration value of $15 \%$ of ionic liquid was obtained. Consequently, the retention remains the same than that obtained in a single step process (21\%), but the recovery of ionic liquid decreases from $55 \%$ to $27 \%$ due to the reduction of permeate volume obtained after three filtration steps. However, although the recovery rate of ionic liquid could be actually considered low for practical purposes, it was possible to remove the undesired compounds.

Further research must be oriented into find more selective membranes which can be used in a two stage filtration process: the membrane used at the first stage has to be able to retain most of the degradation by-products but not the ionic liquid, in order to purify it. The second membrane must retain most of the ionic liquid in order to concentrate it at a great extent before evaporation. Finally, the purified ionic liquid could be then reused for a further cellulose dissolution process.

\section{Recovery of hydrophobic ionic liquids from wastewater}

Ionic liquids which are poorly water soluble $(<5 \mathrm{~g} / \mathrm{L})$ can serve as a co-solvent for biotransformations that involve hydrophobic compounds. After separation of the ionic liquid phase used as cosolvent, a wastewater containing the ionic liquid at its saturation level

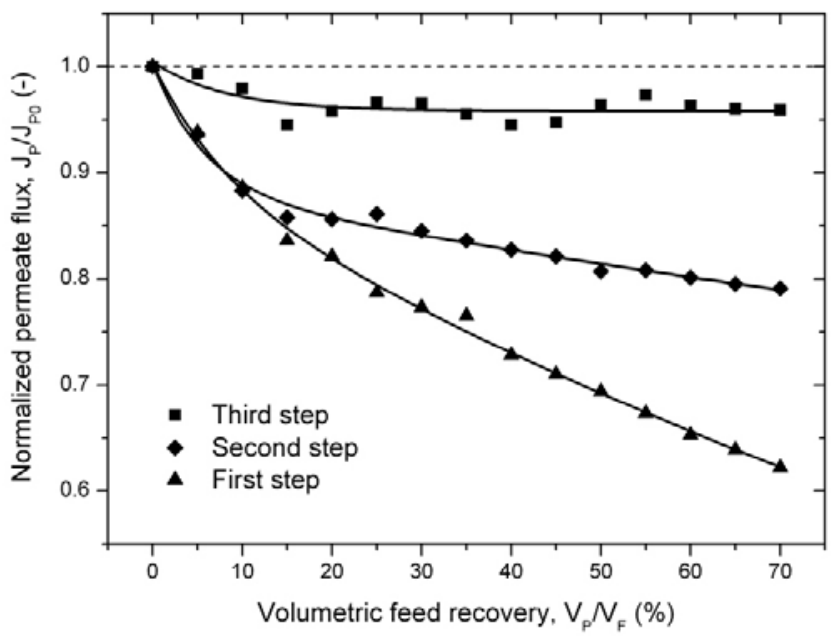

Figure 3: Decrease of the normalized permeate flux with increasing feed recovery rate $\left(V_{p} / V_{F}\right)$ for three successive nanofiltration steps in a dead-end stirred cell $\left(25^{\circ} \mathrm{C}, 35\right.$ bar $)$ using the NF-270 membrane. Permeate from the first step was used as feed for the second step, while permeate from second step was used as feed for the third step. The wastewater contained a mixture of IM14 Cl and IM14 1COO.

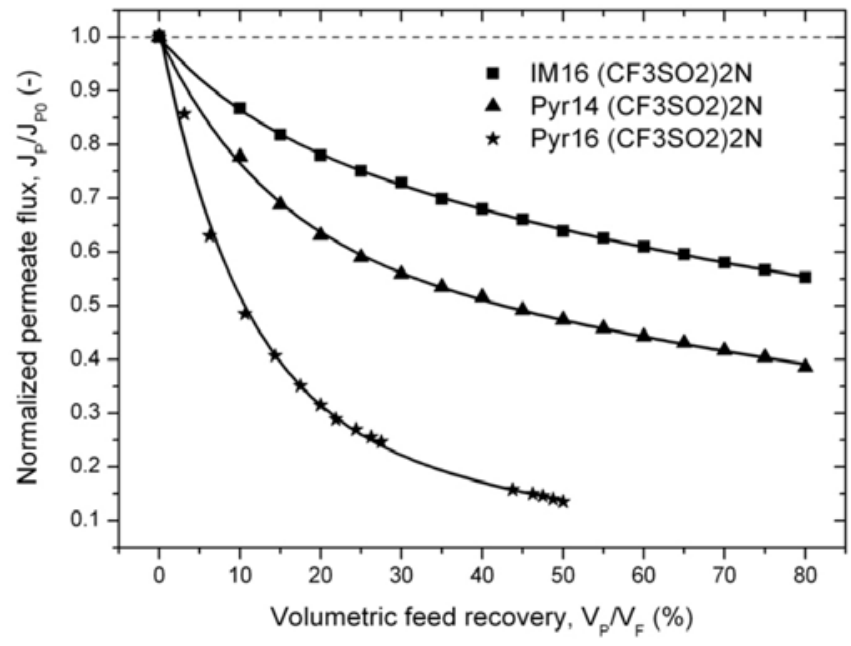

Figure 4: Decrease of the normalized permeate flux with increased recovery rate for three hydrophobic ionic liquids in a dead-end stirred cell $\left(25^{\circ} \mathrm{C}, 35 \mathrm{bar}\right)$. Wastewater samples containing IM16 (CF3SO2)2N and Pyr14 (CF3SO2)2N were filtered using the Desal DK membrane, while the wastewater sample containing Pyr16 (CF3SO2)2N was filtered using the NF-270 membrane. 


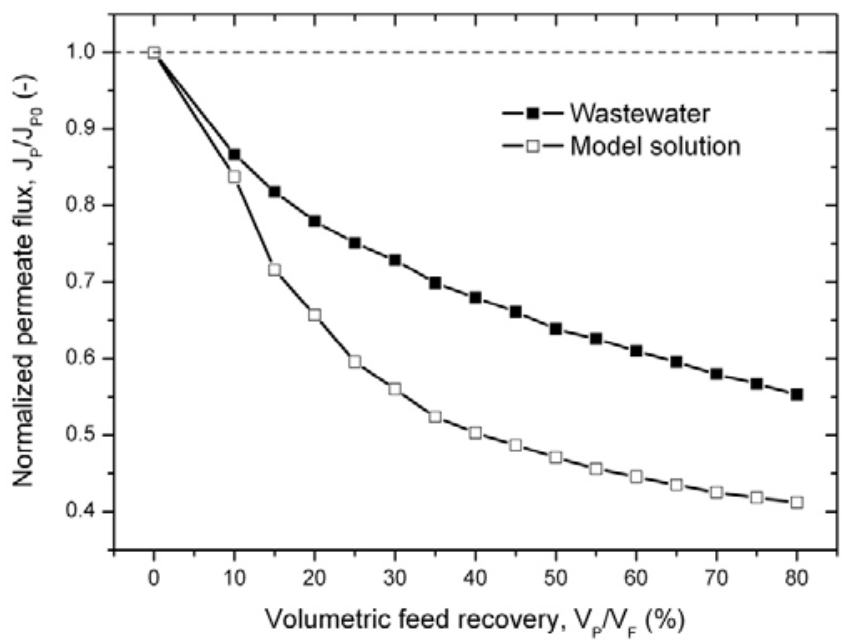

Figure 5: Decrease of the normalized permeate flux with increased recovery rate for solutions containing IM16 (CF3SO2)2N in a dead-end stirred cell $\left(25^{\circ} \mathrm{C}\right.$ 35 bar) by using the Desal DK membrane. Increasing osmotic pressure and other mixture components are responsible for the reduction in permeate flux.

(e.g. $1.82 \mathrm{~kg}$ of IM16 (CF3SO2)2N per $\mathrm{m}^{3}$ reaction batch) remains. In order to recovery these ionic liquid residues, the target is to concentrate continuously the wastewater in order to promote the formation of a second phase of pure ionic liquid, which can be easily separated by well-established phase separation methods. In this case, a membrane with high retention for the ionic liquid is required.

In a first trial, the membrane FilmTec NF-90 was selected, because it showed high retention for several ionic liquids (> 99\%) in previous tests [47]. However, no permeate was obtained by the filtration at $35 \mathrm{bar}$ of a wastewater containing Pyr16 (CF3SO2)2N, while a permeate flux of only $3.5 \mathrm{~L} / \mathrm{m}^{2} \mathrm{~h}$, was obtained for the wastewater containing IM16 (CF3SO2) $2 \mathrm{~N}$, at the same pressure difference. Then, a high retention for the ionic liquid has to be coupled to a reasonable permeate flux. Based on these results, the membrane Desal DK was used for the wastewaters from enzymatic biotransformations, while for the wastewater from whole-cell biotransformation, the membrane FilmTec NF-270 was selected. In all cases, a pronounced reduction of the permeate flux during the concentration process was observed, especially in the case of Pyr16 (CF3SO2)2N (Figure 4).

From these results it can be concluded that the presence of cellular material in wastewater from whole-cell biotransformations (although most of the cells were previously removed by centrifugation) contributes to the clogging of the membranes and reduce strongly the permeate flux. Despite the wastewaters from enzymatic biotransformations could be considered cleaner than those derived from whole-cell biotransformations due to the absence of cellular material, the presence of other components in the mixture (residual 2-octanol and 2-octanone, buffer and/or enzymes) has still an influence on the quantity of permeate obtained. The most part of these undesired materials must be previously removed by micro- or ultrafiltration before any nanofiltration stage. Microfiltration membranes are applied for the separation of whole cells, while ultrafiltration membranes have to be used to retain enzymes $[48,49]$.

Furthermore, during the filtration process the concentration of ionic liquid in retentate goes beyond the solubility of the ionic liquid and the excess of ionic liquid can be expected to leave the solution as a second phase, according to a more stable thermodynamically state. For both IM16 (CF3SO2)2N and Pyr14 (CF3SO2)2N, it was possible to observe in the retentate small drops of a second liquid phase. However, in the case of Pyr16 (CF3SO2)2N it was not possible to observe such a second phase, presumably to the low feed recovery rate achieved $\left(\mathrm{V}_{\mathrm{P}} /\right.$ $\left.\mathrm{V}_{\mathrm{F}}=50 \%\right)$.

In order to establish the effect of the mixture components a second experiment using an aqueous solution of IM16 (CF3SO2) $2 \mathrm{~N}$ was conducted (Table 1).

As expected, higher values were obtained for permeate flux and retention by using the aqueous solution of ionic liquid, leading also to a higher recovery of ionic liquid (almost 76\%). Although the mean permeate flux is higher in the case of the model solution as in the case of the wastewater, its decrease is more remarkable when a model solution of IM16 (CF3SO2)2N was used (Figure 5).

Such behavior can be explained by the increasing osmotic pressure, which can be limiting especially for high concentrations of ionic liquid [39]. For a given process recovery value $\left(\mathrm{V}_{\mathrm{p}} / \mathrm{V}_{\mathrm{F}}\right)$, higher concentrations of ionic liquid can be achieved with the model solution, because the retention is considerably higher (95.2\%) compared to the retention achieved by filtering the wastewater $(63.1 \%)$.

However, in the case of the wastewater, around $50 \%$ of the ionic liquid originally dissolved in the wastewater can be forced to produce a second phase. As a consequence, the recovery of hydrophobic ionic liquids from synthetic solutions was later studied in laboratory scale using the cross-flow equipment especially developed for such a task.

\section{Recovery of hydrophobic ionic liquids from synthetic solutions}

From membrane screening tests using ionic liquid aqueous solutions, it was found that the NF-270 membrane provides the highest permeate fluxes (more than twice the values obtained for the Desal-DK membrane), no matter the ionic liquid employed. The retention values are similar (95\% for IM16 and 97\% for Pyr 16, respectively), which can be explained due to the similarity on their molecular weights. Because the water solubility for both ionic liquids containing the (CF3SO2) $2 \mathrm{~N}$ anion is almost the same (around $2.0 \mathrm{~g} / \mathrm{L}$ ) the Pyr16 (CF3SO2)2N ionic liquid was selected for the tests in the cross-flow cell, due to its low toxicity in all the toxicity tests comprising the UFT test battery [50].

The progress of the concentration process for a model solution containing the Pyr16 (CF3SO2)2N ionic liquid is shown, when no coalescence filter was used (First column, Table 2). At the saturation point a clear feed solution was observed in the feed collector tank $\left(\mathrm{V}_{\mathrm{p}}\right)$ $\mathrm{V}_{\mathrm{F}}=0 \%$ ), but the liquid becomes cloudier as the concentration process proceeds. This indicates that the second phase locally formed inside the modules remains dispersed due to agitation caused by continuous flow. The higher the process recovery, cloudier becomes the liquid in the feed tank. After collecting $50 \%$ of the original feed as permeate, a

\begin{tabular}{|l|l|l|}
\hline Parameter & Wastewater & Model solution \\
\hline Feed concentration, $\mathrm{C}_{\mathrm{F}}(\mathrm{g} / \mathrm{L})$ & 1.826 & 1.838 \\
\hline Mean permeate flux, $\mathrm{J}_{\mathrm{Pm}}\left(\mathrm{L} / \mathrm{m}^{2} \mathrm{~h}\right)$ & 22.2 & 33.1 \\
\hline Retention, $\mathrm{R}(\%)$ & 63.1 & 95.2 \\
\hline Ionic liquid Recovery, $\mathrm{Rec}(\%)$ & 50.5 & 75.6 \\
\hline
\end{tabular}

Table 1: Effect of wastewater components on nanofiltration performance and ionic liquid recovery for IM16 (CF3SO2)2N. Experiments were carried out using a deadend stirred cell $\left(25^{\circ} \mathrm{C}, 35\right.$ bar, $80 \%$ feed recovered as permeate) and the Desal DK membrane was used. 
very cloudy retentate was obtained, which after sedimentation at room temperature (2 days) became clear and many droplets of ionic liquid could be observed at the bottom of the bottle.

However, after removing the retentate stream and proceed to clean the equipment with about 4 liter pure water, it was found that the rinsing water contained an elevated concentration of ionic liquid, around $1.40-1.50 \mathrm{~g} / \mathrm{L}$. This finding indicates that some ionic liquid is coalescing and thus collecting inside the filtration equipment; especially at the pump, because it represents the deepest point of the system. In order to reduce this undesired effect, a coalescence filter was installed between the outlet of the second filtration module and the feed tank. It facilitates the coalescence of the drops as soon as they are formed inside the modules and allow collecting them at the feed tank. In this case, a completely different behaviour inside the feed tank during the concentration experiment was observed, compared to the results obtained without using the coalescence filter (Second column, Table 2).

Without the coalescence filter, no emulsion was observed at a recovery rate of $0 \%$; while two different zones were appreciated by using the coalescence filter. The upper zone was cloudy and corresponds to the emulsion of ionic liquid, while the lower one was clear and corresponds to a saturated solution of ionic liquid. This result confirms the local formation of a second phase inside the filtration modules, and due to the presence of the coalescence filter, the drops are helped during their growing process. This behaviour was observed until a recovery rate around $20 \%$. After that the emulsion was occupying the whole tank in both cases, but it was cloudier as when the coalescence filter was used. Again, a cloudier emulsion can be associated with the presence of bigger drops, indicating that the coalescence filter is serving its purpose.

The installation of the coalescence filter had also an effect on the variation of the permeate flux (Figure 6). The effective coalescence of the drops as well as the presence of the two zones in the feed tank contribute to maintain the permeate flux similar than the permeate flux value at saturation, until a recovery rate of $20 \%$. At this point, the emulsion occupies the whole tank at their effects in the permeate flux began to appear, but less pronounced than those observed when no

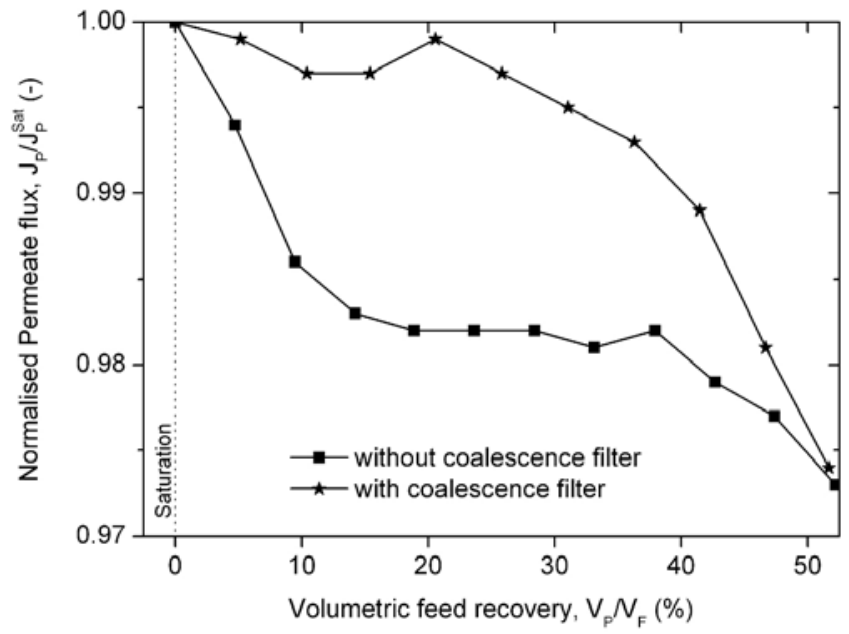

Figure 6: Decrease of the normalized permeate flux with increased recovery rate during the recovery of Pyr16 (CF3SO2) $2 \mathrm{~N}$ by cross-flow filtration $\left(25^{\circ} \mathrm{C}\right.$, $35 \mathrm{bar}, 0.5 \mathrm{~m} / \mathrm{s}$ ) and using the NF-270 membrane. The effect of using a coalescence filter on permeate flux is shown. coalescence filter is installed. Finally, for higher process recovery rates, the mixing effects due to low liquid level are similar for both cases.

The more effective drop size growing reduces not only the additional resistance to the permeating flow across the membrane, but also improves the retention values for the whole process (Table 3). It can be explained in terms of a reduced accumulation of small drops on the membrane surface, because they are forced to coalesce and stay at the feed tank before the solution is pumped again for a further filtration step.

Another discussion point is related to the amount of ionic liquid which can be practically recovered as second phase. The mass balance, represented by Eq. 2, allows the determination of the amount of ionic liquid formed as second phase with respect to the ionic liquid original dissolved in feed. This recovery rate of ionic liquid is denominated total recovery. It exhibits values between $66 \%$ and $69 \%$ (Table 3), very similar to those obtained during the experiments in the dead-end filtration equipment (72\%).

Theoretically, once the membrane, the operational conditions and the extent of concentration $\left(\mathrm{V}_{\mathrm{P}} / \mathrm{V}_{\mathrm{F}}\right)$ are selected, the total recovery can

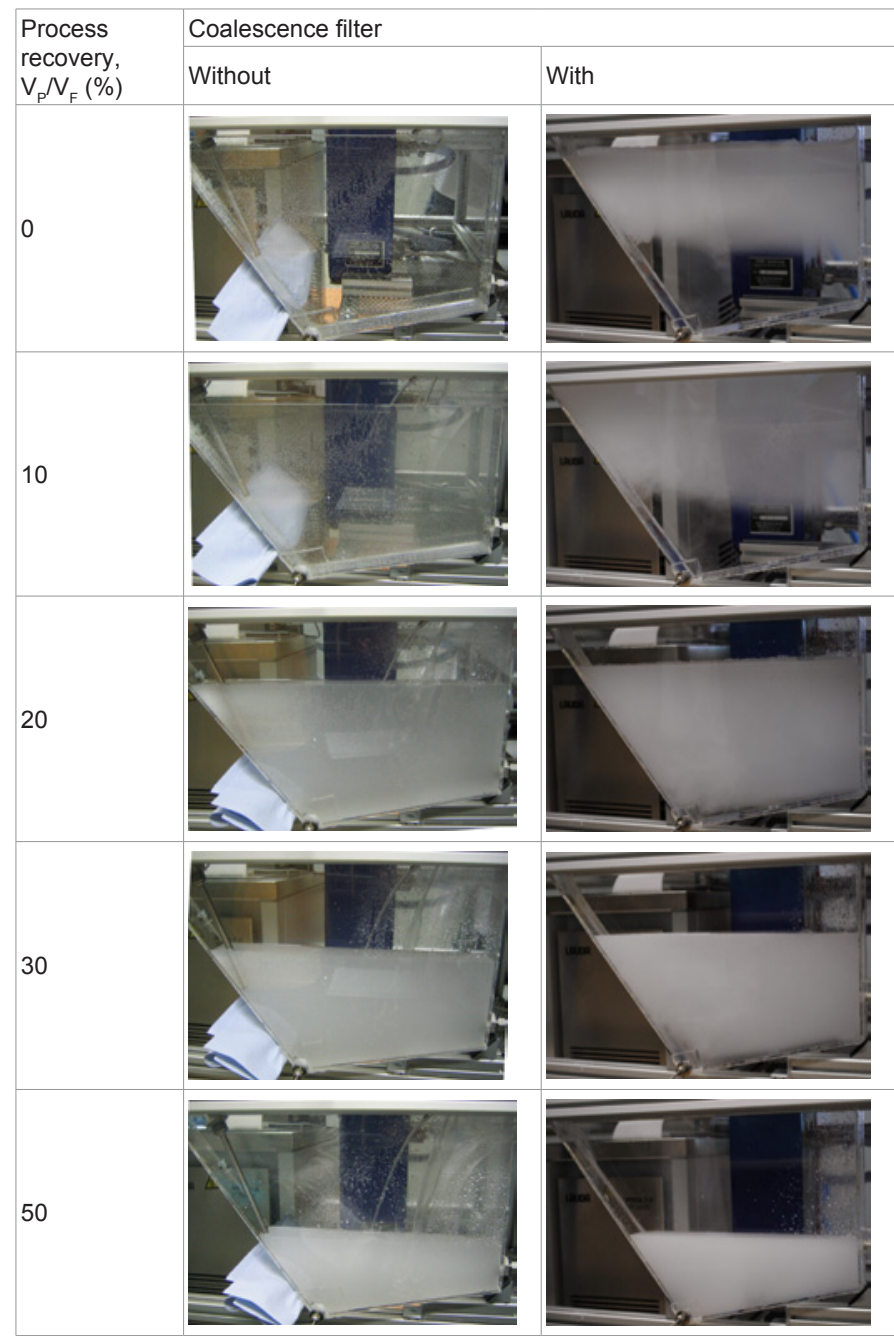

Table 2: Comparison of the changes observed in the feed tank during the concentration process of Pyr16 (CF3SO2)2N when a coalescence filter is used. Experiments were carried out using a cross-flow filtration module $\left(25^{\circ} \mathrm{C}, 35\right.$ bar, 0.5 $\mathrm{m} / \mathrm{s}$ ) and the NF-270 membrane was used. 


\begin{tabular}{|l|l|l|}
\hline Parameter & Without coalescence filter & $\begin{array}{l}\text { With coalescence } \\
\text { filter }\end{array}$ \\
\hline Initial permeate flux, $\mathrm{J}_{P}$ Sat $\left(\mathrm{L} / \mathrm{m}^{2} \mathrm{~h}\right)$ & 197 & 186 \\
\hline Retention, R (\%) & 92.4 & 94.8 \\
\hline Total Recovery, Rec (\%) & 66.4 & 68.6 \\
\hline $\begin{array}{l}\text { Effective Recovery at lab scale, } \\
\text { Rec-eff-lab (\%) }\end{array}$ & 15.1 & 33.4 \\
\hline
\end{tabular}

Table 3: Effect of using a coalescence filter on nanofiltration performance and ionic liquid recovery for Pyr16 (CF3SO2)2N. Experiments were carried out using a cross-flow filtration module $\left(25^{\circ} \mathrm{C}, 35 \mathrm{bar}, 0.5 \mathrm{~m} / \mathrm{s}\right)$ and the $\mathrm{NF}-270$ membrane was used.

be considered as a fixed value, and in consequence, it represents the maximal recovery rate possible. However, the recovery of ionic liquid is not complete, and a new term denominated effective recovery at lab scale is needed. It represents the amount of ionic liquid as second phase formed that is not dissolved by the rinsing water and it can be recovered with the retentate stream. It can be also calculated using a modified material balance (Eq. 3). Comparing the values of effective recovery at lab scale for both experiments (Table 3), it is evident that the use of a coalescence filter improves the recovery of ionic liquid due to an effective coalescence of the drops after their formation.

In this context, considering a total recovery rate of $70 \%$ as acceptable, the first challenge is related to increase the effective recovery rate in order to reach a value as close as possible to the total recovery rate. Once this aim is achieved, another challenge for further improvement deals with increasing the total recovery rate.

To increase the effective recovery rate, heterogeneous nucleation must be enhanced. The locally formed supersaturated solution should be forced to nucleate and grow in a large extent before to be collected and separated, as it was achieved by using the coalescence filter. Seeding with pure ionic liquid could be an option, following the same principle of crystallization. Furthermore, an effective second phase separation is required, which should not affect the actual operating concept or the equipment configuration. For instance, the use of a lamellar separator which also acts as feed tank is in agreement with both conditions and could be used. Finally, dead zones inside the equipment are ideal places for ionic liquid settling and they must be avoided by an adequate equipment configuration.

In order to increase the total recovery rate, a modified batch process (an equal volume of fresh feed is added to the process tank to keep it at the same level as permeate is removed) can be also tested. Finally, optimization of operational conditions and the use of more selective membranes in order to increase both retention and permeate flux should be also taken into account for further developments.

\section{Conclusions}

The recovery of ionic liquids by nanofiltration could be achieved with wastewaters derived from two different ionic liquids applications. In the case of hydrophilic ionic liquids, they are recovered as an aqueous solution almost free of undesired compounds; while in the case of hydrophobic ionic liquids, they can be obtained as a second phase of ionic liquid. Recovery targets up to $50 \%$ can be realized with the tested membranes and without any wastewater pretreatment. However, for high recovery targets either pretreated wastewaters or membranes with higher retention for the ionic liquids are required.

Considering that most of the hydrophobic ionic liquids known up to date are either toxic or not easily biodegradable, their recovery from wastewater will allow the establishment of those potential applications of ionic liquids which are till now threatened, once the associated risks of environmental damages and economical losses are successfully overcame.

Despite the few studies already published about the use of nanofiltration for separation of ionic liquids from aqueous solutions only paid attention to hydrophilic ionic liquids, in this study was demonstrated by using synthetic solutions, that the separation of hydrophobic ionic liquids is both necessary and possible.

However, despite the use of nanofiltration for such purposes exhibits an encouraging future, when dealing with the quest of applications for ionic liquids (or even for other novel and trendy chemicals) the "keep it simple and straightforward" principle must be always considered. That means that all endeavors should be focused on the development of processes with zero waste production, while recovery operations like nanofiltration should remain always as a last option.

\section{Acknowledgements}

The authors wish to thank Birgit Kosan (TITK), Jeffrey Lutje-Spelberg (Julich Chiral Solutions) and Danielle Dennewald (Institute of Biochemical Engineering TUM) for providing the wastewater samples. The support of Jolanta Kumirska (Department of Environmental Analysis, University of Gdansk, Poland) for performing the cellulose degradation by-products content measurements is gratefully acknowledged. This work was partially supported by the German Federal Ministry of Education and Research (BMBF), Grant N 03X2011D.

\section{References}

1. Freemantle M (2010) An introduction to ionic liquids, RSC Publishing Cambridge.

2. Plechkova NV, Seddon KR (2008) Applications of ionic liquids in the chemical industry. Chemical Society Reviews 37: 123-150.

3. Fernández JF, Neumann J, Thöming J (2011) Regeneration, recovery and removal of ionic liquids. Current Organic Chemistry 15: 1992-2014.

4. Scammells PJ, Scott JL, Singer RD (2005) lonic liquids: the neglected issues Australian Journal of Chemistry 58: 155-169.

5. Zhao DB, Liao YC, Zhang ZD (2007) Toxicity of ionic liquids. Clean: Soil, Air, Water 35: 42-48.

6. Hermanutz F, Meister F, Uerdingen E (2006) New developments in the manufacture of cellulose fibers with ionic liquids. Chemical Fibers International 6: $342-344$.

7. van Rantwijk F, Madeira Lau R, Sheldon RA (2003) Biocatalytic transformations in ionic liquids. Trends in Biotechnology 21: 131-138.

8. Lou W, Zong M, Wu H, Xu R (2004) Recent progress on biocatalysis and biotransformations in ionic liquids. Chinese Journal of Chemical Engineering 12: $543-549$

9. Swatloski RP, Spear SK, Holbrey JD, Rogers RD (2002) Dissolution of cellose with ionic liquids. Journal of the American Chemical Society 124: 4974-4975

10. Michels C, Kosan B, Meister F. (2005) Verfahren und Vorrichtung zu Herstellung von Formkörpern aus Cellulose. DE Patent 102004031025 B3.

11. Kosan B, Michels C, Meister F (2008) Dissolution and forming of cellulose with ionic liquids. Cellulose 15: 59-66.

12. Bentivoglio G, Röder T, Fasching $M$, Buchberger $M$, Schottenberger $H$, et al (2006) Cellulose with chloride-based ionic liquids. Lenzinger Berichte 86: 154 161.

13. Rosenau T, Potthast A, Milacher W, Hofinger A, Kosma P (2004) Isolation and identification of residual chromophores in cellulosic materials. Polymer 45 6437-6443.

14. Rosenau T, Potthast A, Sixta H, Kosma P (2001) The chemistry of side reactions and byproduct formation in the system NMMO/cellulose (Lyocell process). Progress in Polymer Science 26: 1763-1837.

15. Goldberg K, Schroer K, Lütz S, Liese A (2007) Biocatalytic ketone reduction - a powerful tool for the production of chiral alcohols - part I: processes with isolated enzymes. Applied Microbiology and Biotechnology 76: 237-248. 
Citation: Fernández JF, Bartel R, Bottin-Weber U, Stolte S, Thöming J (2011) Recovery of lonic Liquids from Wastewater by Nanofiltration. J Membra Sci Technol S4:001. doi:10.4172/2155-9589.S4-001

16. Wasserscheid $P$, Welton $T$ (2003) lonic liquids in synthesis. Wiley-VCH, Weinheim

17. Eckstein M, Villela Filho M, Liese A, Kragl U (2004) Use of an ionic liquid in a two-phase system to improve an alcohol dehydrogenase catalysed reduction. Chemical Communications 9: 1084-1085.

18. Hussain W, Pollard DJ, Truppo M, Lye GJ (2008) Enzymatic ketone reductions with co-factor recycling: Improved reactions with ionic liquid co-solvents. Journal of Molecular Catalysis B: Enzymatic 55: 19-29.

19. Pfruender H, Amidjojo M, Kragl U, Weuster-Botz D (2004) Efficient whole-cel biotransformation in a biphasic ionic liquid/water system. Angewandte Chemie, International Edition 43: 4529-4531.

20. Bräutigam S, Bringer-Meyer S, Weuster-Botz D (2007) Asymmetric whole cell biotransformations in biphasic ionic liquid/water-systems by use of recombinan Escherichia coli with intracellular cofactor regeneration. Tetrahedron: Asymmetry 18: 1883-1887.

21. Bräutigam S, Dennewald D, Schürmann M, Lutje-Spelberg J, Pitner WR, et al. (2009) Whole-cell biocatalysis: Evaluation of new hydrophobic ionic liquids for efficient asymmetric reduction of prochiral ketones. Enzyme and Microbia Technology 45: 310-316.

22. Goldberg K, Schroer K, Lütz S, Liese A (2007) Biocatalytic ketone reduction - a powerful tool for the production of chiral alcohols - part II: whole-cell reductions. Applied Microbiology and Biotechnology 76: 249-255

23. Dennewald D, Pitner WR, Weuster-Botz D (2011) Recycling of the ionic liquid phase in process integrated biphasic whole-cell biocatalysis. Process Biochemistry 46: 1132-1137.

24. McFarlane J, Ridenour WB, Luo H, Hunt RD, DePaoli DW et al. (2005) Room temperature ionic liquids for separating organics from produced water Separation Science and Technology 40: 1245-1265.

25. Anthony JL, Maginn EJ, Brennecke JF (2001) Solution thermodynamics of imidazolium-based ionic liquids and water. Journal of Physical Chemistry B 105: 10942-10949.

26. Gutowski KE, Broker GA, Willauer HD, Huddleston JG, Swatloski RP et al. (2003) Controlling the aqueous miscibility of ionic liquids: Aqueous biphasic systems of water-miscible ionic liquids and water-structuring salts for recycle, metathesis, and separations. Journal of the American Chemical Society 125: 6632-6633.

27. Bridges NJ, Gutowski KE, Rogers RD (2007) Investigation of aqueous biphasic systems formed from solutions of chaotropic salts with kosmotropic salts (saltsalt $A B S)$. Green Chemistry 9: 177-183.

28. Trindade JR, Visak ZP, Blesic M, Marrucho IM, Coutinho JAP et al. (2007) Salting-out effects in aqueous ionic liquid solutions: Cloud-point temperature shifts. Journal of Physical Chemistry B 111: 4737-4741.

29. Najdanovic-Visak V, Canongia Lopes JN, Visak ZP, Trindade J, Rebelo LPN (2007) Salting-out in aqueous solutions of ionic liquids and $\mathrm{K}_{3} \mathrm{PO}_{4}$ : Aqueous biphasic systems and salt precipitation. International Journal of Molecular Sciences 8: 736-748.

30. Deng Y, Chen J, Zhang D (2007) Phase Diagram Data for Several Salt + Salt Aqueous Biphasic Systems at $298.15 \mathrm{~K}$. Journal of Chemical and Engineering Data 52: 1332-1335.

31. Wu B, Zhang Y, Wang H, Yang L (2008) Aqueous biphasic systems of hydrophilic ionic liquids + sucrose for separation. Journal of Chemical and Engineering Data 53: 983-985.

32. Wu B, Zhang $Y$, Wang $H$, Yang $L$ (2008) Phase behavior for ternary systems composed of ionic liquid + saccharides + water. Journal of Physical Chemistry B 112: 6426-6429.

33. Wu B, Zhang $Y$, Wang H, Yang $L$ (2008) Temperature dependence of phase behavior for ternary systems composed of ionic liquid + sucrose + water Journal of Physical Chemistry B 112: 13163-13165.

34. Scurto AM, Aki SNVK, Brennecke JF (2003) Carbon dioxide induced separation of ionic liquids and water. Chemical Communications 5: 572-573.

35. Zhang Z, Wu W, Gao H, Han B, Wang B, et al. (2004) Tri-phase behavio of ionic liquid-water- $\mathrm{CO}_{2}$ system at elevated pressures. Physical Chemistry Chemical Physics 6: 5051-5055.

36. Kröckel J, Kragl U (2003) Nanofiltration for the separation of nonvolatile products from solutions containing ionic liquids. Chemical Engineering and Technology 26: 1166-1168.

37. Wu B, Zhang YM, Wang HP (2009) Non-equilibrium thermodynamic analysis of transport properties in the nanofiltration of ionic liquid-water solutions. Molecules 14: 1781-1788.

38. Solá Cervera JL, König A (2010) Recycling concept for aluminium electrodeposition from the ionic liquid system EMIM[Tf $\mathrm{N}_{2}-\mathrm{AICl}_{3}$. Chemical Engineering and Technology 33: 1979-1988.

39. Haerens K, Van Deuren S, Matthijs E, Van der Bruggen B (2010) Challenges for recycling ionic liquids by using pressure driven membrane processes. Green Chemistry 12: 2182-2188.

40. Trevelyan WE, Forrest RS, Harrison JS (1952) Determination of yeast carbohydrates with the anthrone reagent, Nature 170: 626-627.

41. Sescousse R, Gavillon R, Budtova T (2011) Aerocellulose from cellulose-ionic liquid solutions: Preparation, properties and comparison with cellulose- $\mathrm{NaOH}$ and cellulose-NMMO routes. Carbohydrate Polymers 83: 1766-1774.

42. Rosenau T, Potthast A, Milacher W, Adorjan I, Hofinger A, et al. (2005) Discoloration of cellulose solutions in $\mathrm{N}$-methylmorpholine-N-oxide (Lyocell). Part 2: Isolation and identification of chromophores. Cellulose 12: 197-208.

43. Rosenau T, Potthast A, Adorjan I, Hofinger A, Sixta H, et al. (2002) Cellulose solutions in $\mathrm{N}$-methylmorpholine-N-oxide (NMMO) - degradation processes and stabilizers. Cellulose 9: 283-291.

44. Adorjan I, Potthast A, Rosenau T, Sixta H, Kosma P (2005) Discoloration of cellulose solutions in $\mathrm{N}$-methylmorpholine-N-oxide (Lyocell). Part 1: Studies of model compounds and pulps. Cellulose 12: 51-57.

45. Ebner G, Schiehser S, Potthast A, Rosenau T (2008) Side reaction of cellulose with common 1-alkyl-3-methylimidazolium-based ionic liquids. Tetrahedron Letters 49: 7322-7324

46. Feng D, Li L, Yang F, Tan W, Zhao G, et al. (2011) Separation of ionic liquid [Mmin][DMP] and glucose from enzymatic hydrolysis mixture of cellulose using alumina column chromatography. Applied Microbiology and Biotechnology 91 : 399-405.

47. Fernández JF, Chilyumova E, Waterkamp D, Thöming J (2008) lonic liquid recovery from aqueous solutions by cross-flow nanofiltration. Proceedings of the $10^{\text {th }}$ World Filtration Congress.

48. Strathmann, $H$ (1985) Membranes and membrane processes in biotechnology Trends in Biotechnology 3:112-118.

49. Liese A, Seelbach K, Wandrey C (2006) Industrial biotransformations. (2nd edn), Wiley $\mathrm{VCH}$, Weinheim.

50. The UFT/Merck lonic Liquids Biological Effects Database (2011). http://www il-eco.uft.uni-bremen.de/ 